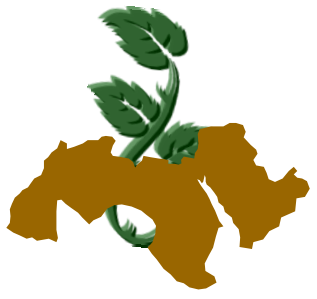

Arab Univ.

\title{
DETERMINATION OF PESTICIDES RESIDUES IN HONEY BY USING DIFFERENT EXTRACTION METHODS AND GAS CHROMATOGRAPHY WITH ELECTRON CAPTURE DETECTION
}

\author{
Abd Al-Rahman ${ }^{1, a}$, Sh.H. \\ 1- Dept. of Pesticide Residues and Environmental Pollution, Central Agricultural Pesti- \\ cides Laboratory (CAPL), ARC, Dokki, Giza, Egypt
}

a) E. Mail: drsherif_hussein@yahoo.com

Keywords: Honey; Pesticide residues; Gas Chromatography-electron capture detector (GC-ECD)

\section{ABSTRACT}

In this study three analytical methods for the extraction of pesticide residues in spiked honey samples were evaluated. They have been applied to identification and quantification of targeted thirty five pesticides from different chemical groups and the possibility of identification of any other eluting compounds. Such methods are based on liquidliquid extraction (LLE) with different organic solvents; ethyl acetate (method_1), n-hexane (method_2) and (petroleum ether: ethyl acetate 80:20 $\mathrm{v} / \mathrm{v})$ (method_3), followed by clean-up with florisil and quantification by gas chromatographyelectron-capture detection (GC-ECD). Recoveries of the applied spiked samples were ranged from $(64.86-113.01 \%),(64.67-111.28 \%)$ and $(67.48$ - $107.82 \%)$ with the three mentioned methods, respectively. The best results were obtained from ethyl acetate method.

\section{INTRODUCTION}

The persistence organic pollutants (POPs) constitute one of the most serious dangerous by the environmental contaminants. The occurrence of pesticide residues in the food chain has already been reported in several studies. The environmental contamination by persistent pesticide residues has been widely documented in soil, plants, water, milk, and biological fluids (Pico, et al 1995). The POPs has a lipophilic nature, so it can be enter into the food chain by accumulating in fats, but can also be present in non-fatty products, even those which have not been treated directly with them (Fernandez, et al 1995). It can be present in honey by direct treatment of plants and/or migration from wax to honey. Since honeybees travel for long distances and come close to many plants, so honey may be an easily accessible environmental pollution indicator (Marzycka, 2002). Monitoring of pesticide residues in bee products is necessary to consumer health (Fernandez, et al 2002). Honey is a natural product that must be free of any chemical contaminants and safe for human consumption, because it is traditionally used in child, old and ill people foods and its quality must be proved (Tsipi, et al 1999). However, to date European Union (EU) legislation has established the maximum residue limits (MRL) in honey for only three acaricides, namely amitraz, coumaphos and cymiazole as, 0.2, 0.1 and $1 \mu \mathrm{g} / \mathrm{g}$ respectively (Herrera, et al 2005 and Council Directive/EC 2001). Many methods have been reported for the determination of pesticides in honey. Most used methods for pesticide residues determination is based on liquidliquid extraction (LLE) performed with water nonmiscible solvents, such as ethyl acetate, petroleum ether, or $n$-hexane and dichloromethane (Tsipi, et al 1999). After LLE extraction a clean-up with different adsorbents may be necessary, florisil or silica gel or activated carbon (Jimenez, et al 1998). GC-ECD has been widely applied as the preferred technique for the identification and quantification of pesticide residues. The purpose of this work was to develop a rapid, sensitive and easy method for the analysis of 35 pesticide residues with GC-ECD in honey spiked samples.

\section{MATERIALS AND METHODS}




\section{1- Chemicals}

The tested thirty five pesticides standards belong different chemical groups were organophosphorous as trichlorofon, carbamate as furan, [organochlorine as (alpha, beta, gamma and delta) $\mathrm{HCH},(o, p$ and p,p) DDT, o,p-DDE, p,p-DDD, (alpha and beta) endosulfan, aldrin, endrin, dieldrin, heptachlor and heptachlor-epoxide], (triazine as atrazine), (triazinone as metrbuzine) (triazole as Propconazol and Epoxiconazol), (neonicotinoid as acetamiprid)and (pyrethroids as tetramethrin, lampada-cyhalothrin, permithrin, cyfluthrin, cypermethrin, fenvalerate and deltamethrin) were obtained from Dr. Ehrenstofer GmbH Germany. Petroleum ether, diethyl ether, $n$-hexane, and ethyl acetate (for pesticides residue analysis grade) were obtained from Merck Co. Stock solution of each pesticide was prepared separately at $0.5 \mathrm{mg} / \mathrm{ml}$ in $n$ hexane-acetone $(95: 5, \mathrm{v} / \mathrm{v})$. Standard solutions were prepared at $10 \mu \mathrm{g} / \mathrm{ml}$, and then stored at $4^{\circ} \mathrm{C}$. Working solutions were prepared between 0.2 to $2.0 \mu \mathrm{g} / \mathrm{ml}$. Deionized water was prepared from a Milli-Q system (Millipore, Bedford, MA, USA). Florisil 60-100 mesh was obtained from Merck (Germany), and activated in an oven at $150{ }^{\circ} \mathrm{C}$ for $12 \mathrm{~h}$, cooled in a desiccator, and a portion was deactivated to $2 \%$ with water. Sodium sulfate anhydrous analytical grade was obtained from Merck (Germany).

\section{2- Apparatus}

Rotary vacuum evaporator from Buchi provided with water bath (France), the centrifuge MIKRO22R from Hettich GmbH (Germany) and highspeed vortex type: pv-1 form Grant-bio Cambridge Ltd (England) was used. Gas Chromatography used was Agilent 6890 series, with Electron capture detector specifies for organochlorine pesticides and HB-5 capillary column $(30 \mathrm{~m} \times 0.25 \mathrm{~mm})$ coated with a $0.25 \mu \mathrm{m}$ thick film of $5 \%$ phenylmethylpolysiloxane was used for separation of the used pesticides.

\section{3- Recoveries}

For recovery studies, $0.25 \mathrm{ml}$ of the working solution containing tested pesticides mixture was added to $5 \mathrm{~g}$ of honey, and allowed to stand for 15 min before extraction. Three replicates in a series of measurements were used. Blank sample was also considered.

\section{4- Extraction methods}

\section{1- Method_1 (ethyl acetate)}

Five grams of honey was dissolved with $50 \mathrm{ml}$ $4 \%$ aqueous solution of sodium sulfate, shaked vigorously and extracted with three portions of ethyl acetate $3 \times 20 \mathrm{ml}$. When emulsion formed it was broken by centrifugation at $3000 \mathrm{rpm}$ for 10 min. The organic phase was dried by anhydrous sodium sulfate.

\section{2- Method_2 (n-hexane)}

Five grams of honey was dissolved with $10 \mathrm{ml}$ of deionized, water shaked vigorously and extracted with three portions of $20 \mathrm{ml}$-hexane. When emulsion formed it was quickly broken by centrifuging at $3000 \mathrm{rpm}$ for $10 \mathrm{~min}$. The organic phase was dehydrated by anhydrous sodium sulfate.

\section{3- Method_3 (petroleum ether: ethyl ace- tate $80: 20 \mathrm{v} / \mathrm{v}$ )}

Five grams of honey was heated in water bath at $35^{\circ} \mathrm{C}$ for $15 \mathrm{~min}$ and dissolved with $50 \mathrm{ml}$ of deionized water, shake vigorously and extracted with $3 \times 20 \mathrm{ml}$ of (petroleum ether : ethyl acetate 80:20 $\mathrm{v} / \mathrm{v}$ ) then shaken by magnetic stirring for $15 \mathrm{~min}$. When emulsion formed it was broken by centrifugation at $3000 \mathrm{rpm}$ for $10 \mathrm{~min}$. The organic phase was dried by filtering on anhydrous sodium sulfate, and concentrated to $1 \mathrm{ml}$.

\section{5- Clean-up procedure}

The concentrated extract was loaded onto a mini-column filled with $2 \mathrm{~g}$ florisil and $1 \mathrm{~g}$ anhydrous sodium sulfate, prerinsed with $10 \mathrm{ml} \mathrm{n}$-hexane. The elution was performed with $25 \mathrm{ml}$ of $5 \%$ of diethyl ether in $\mathrm{n}$-hexane. The eluate was concentrated to dryness in $5 \mathrm{ml}$ glass tube and redissolved in $1 \mathrm{ml}$ of $n$-hexane for analysis.

\section{6- Gas chromatography with electron-capture detector}

Gas Chromatography Agilent 6890 series containing auto-sampler Agilent 7883 injector, with $63 \mathrm{Ni}$ Electron capture detector was used for quantification the tested pesticide residues and a fused silica capillary column HB-5 $(30 \mathrm{~m} \times 0.25 \mathrm{~mm} \times$ $0.25 \mu \mathrm{m}$ ) was used for the separation. Chromatographic conditions were adjusted as follows:

The temperature program applied was $120^{\circ} \mathrm{C}$ held for $1 \mathrm{~min}$ and programmed at $20^{\circ} \mathrm{C} / \mathrm{min}$ to 
$180^{\circ} \mathrm{C}$ held for $2 \mathrm{~min}$ and programmed at $5 \mathrm{C} / \mathrm{min}$ to $220^{\circ} \mathrm{C}$, held for $5 \mathrm{~min}$ and finally programmed at $3{ }^{\circ} \mathrm{C} / \mathrm{min}$ to $245^{\circ} \mathrm{C}$, held for $30 \mathrm{~min}$. The injection was carried out with split/splitless injection port at $270{ }^{\circ} \mathrm{C}$, and injection volume was $1 \mu$ l. The detector temperature was $290{ }^{\circ} \mathrm{C}$. Gases used were: Nitrogen as carrier gas at $2.5 \mathrm{ml} / \mathrm{min}$, with mode constant flow + make-up flow at combined flow $60.0 \mathrm{ml} / \mathrm{min}$. The external standard method was used for quantifications by comparing peak areas of the standard with the peaks of extracts at the same retention time.

\section{7- Statistical analysis procedures}

The data were subjected to statistical analysis by two-way ANOVA test using SPSS software for windows version 10.0. Statistical significant differences between obtained recoveries from all methods were carried by Duncan's multiple range (L.S.RD.) $p \leq 0.05$.

\section{RESULTS AND DISCUSSION}

The major objective of this study was the optimization of the extraction methods to reduce the baseline noise in order to the merits of the GCECD method in identification and quantitation of pesticide residues in honey.

The choice of solvent(s) is one of the most crucial decisions to be made when developing a multiresidue method for the determination of pesticides. Solvents with high polarity, such as dichloromethane, acetone and ethyl acetate or their mixtures, should be considered in order to increase the extraction efficiency accordingly (Zhen, et al 2006).

With the view to obtain a more adequate methods for optimization of the extraction and quantification method of the pesticide residues in honey, three liquid-liquid extraction methods by using ethyl acetate, $n$-hexan and mixture of (petroleum ether : ethyl acetate $80: 20 \mathrm{v} / \mathrm{v}$ ) were evaluated. Such evaluations were included the GC conditions, extraction method and statistical parameters. The GC-ECD Parameters and conditions observed achieved good separation of thirty five pesticides belongs to different chemical groups within $<45$ min and no interference was observed in honey samples when the chromatographic parameters are carried out as illustrated in Fig. (1), this is in agreement with (Tsipi, et al 1999) who reported that the matrix interference during analysis of honey in the GC-ECD system was limited and the ECD detector response for target compounds was linear in the concentration range 0.2 to $40 \mu \mathrm{g} / \mathrm{L}$.

Calibration curves were constructed from peak areas versus pesticide concentrations. Limits of detection (LODs) of the followed methods for the studied pesticides were calculated by weighing $5.0 \mathrm{~g}$ sample, final volume to $1.0 \mathrm{ml}$ and injection 1.0ul (Zhen et al 2006).

Data in Table (1), show the results of recoveries and standard deviation obtained from quantitative analysis of 35 pesticides in spiked honey samples with different amounts $(0.2-2.0 \mu \mathrm{g} / \mathrm{kg})$. The studied methods of analysis showed differences in the number of the detected pesticides. Method_1 was detect thirty three pesticides with recoveries percent ranged from $(64.86-113.01) \%$, and it can't detect two pesticides dicofol and metrbuzine. The other methods were detected thirty one pesticides with recovery percent ranged from (64.67 $111.28)$ and $(63.48$ - 107.82) \% with method_2 and method_3 respectively. It can't detect both of trichlorofon and furan while dicofol was detected, but the recovery percent was less than $50 \%$ by these two methods.

Statistical data obtained from the three tested methods indicated that the mean difference in mean of total recovery percents was significant at the level $(0.05)$ between methods. The mean of total recovery percents for the three tested methods were $82.78,77.69$ and $81.25 \%$ with method 1 , 2 and 3 respectively. Each method was in separate statistical group a, b and c Table (2).

Recoveries were assessed, by comparing chromatograms of calibration standard with final extracts of the spiked honey samples with the same calibration standards, (Tahboub, et al 2006).

Finally ethyl acetate method achieved the best results with respect to extraction efficiency with thirty three pesticides among the studied thirty five tested pesticides This data is in agreement with the finding of (Blasco, et al 2004) who reported that the best result for fortification levels between $(10-100 \mu \mathrm{g} / \mathrm{kg})$, were obtained from extracting with ethyl acetate.

\section{CONCLUSION}

In brief all of the three tested methods are suitable for the determination pesticide residues in honey, each of these methods can be used depending on available chemical facilities. The GC- 
Table 1. Retention times, fortification levels, detection limits, mean percentages of recovery and standard deviation of 35 pesticides by three different methods of extraction in honey $(n=3)$

\begin{tabular}{|c|c|c|c|c|c|c|c|}
\hline \multirow{2}{*}{ No. } & \multirow{2}{*}{ Pesticides } & \multirow{2}{*}{$\begin{array}{l}\text { Retention time } \\
\text { (s) }\end{array}$} & \multirow{2}{*}{$\begin{array}{c}\text { Fortification } \\
\text { level } \\
\mu \mathrm{g} / \mathrm{kg} \\
\end{array}$} & \multirow{2}{*}{$\begin{array}{c}\text { Limit of } \\
\text { detection } \\
\mathrm{mg} / \mathrm{kg}\end{array}$} & \multicolumn{3}{|c|}{ Mean percentage of Recovery \pm S.D. } \\
\hline & & & & & Method_1 & Method_2 & Method_3 \\
\hline 1 & Trichlorofon & 1.22 & 0.5 & 0.05 & $66.30 \pm 1.02$ & 0.00 & 0.00 \\
\hline 2 & Furan & 1.26 & 6.0 & 0.04 & $64.86 \pm 0.67$ & 0.00 & 0.00 \\
\hline 3 & Dicofol & 1.69 & 8.0 & 0.01 & 0.00 & $16.14 \pm 1.49$ & $46.76 \pm 0.74$ \\
\hline 4 & Linuron & 3.37 & 30 & 0.05 & $98.15 \pm 1.84$ & $82.76 \pm 0.62$ & $88.0 \pm 0.80$ \\
\hline 5 & Alpha-HCH & 6.84 & 0.8 & 0.004 & $68.01 \pm 1.48$ & $64.67 \pm 2.54$ & $67.48 \pm 0.35$ \\
\hline 6 & Atrazin & 7.39 & 80 & 0.02 & $109.75 \pm 2.55$ & $103270 \pm 1.10$ & $105.62 \pm 0.7$ \\
\hline 7 & Beta-HCH & 7.5 & 2.0 & 0.001 & $86.28 \pm 0.97$ & $85.91 \pm 0.58$ & $98.86 \pm 0.77$ \\
\hline 8 & Gama-HCH & 7.67 & 1.0 & 0.001 & $70.88 \pm 0.73$ & $67.97 \pm 0.52$ & $69.43 \pm 0.40$ \\
\hline 9 & Delta-HCH & 8.32 & 1.0 & 0.005 & $87.01 \pm 0.56$ & $75.35 \pm 0.54$ & $88.34 \pm 0.12$ \\
\hline 10 & Metrbuzin & 9.29 & 2.0 & 0.005 & 0.00 & $68.20 \pm 0.85$ & $63.10 \pm 0.32$ \\
\hline 11 & Venclozolin & 9.46 & 2.0 & 0.01 & $88.29 \pm 0.92$ & $80.16 \pm 0.26$ & $91.47 \pm 0.98$ \\
\hline 12 & Heptachlor & 9.7 & 1.0 & 0.08 & $70.18 \pm 1.70$ & $67.06 \pm 0.17$ & $59.97 \pm 1.54$ \\
\hline 13 & Aldrin & 10.78 & 1.6 & 0.005 & $113.01 \pm 1.60$ & $111.28 \pm 2.88$ & $107.82 \pm 1.89$ \\
\hline 14 & $\begin{array}{l}\text { Heptachlor- epox- } \\
\text { ide }\end{array}$ & 11.09 & 1.0 & 0.09 & $66.04 \pm 1.37$ & $98.89 \pm 2.01$ & $88.69 \pm 0.54$ \\
\hline 15 & Alpha-Endosulfan & 12.25 & 2.0 & 0.05 & $85.59 \pm 0.36$ & $80.98 \pm 1.30$ & $89.60 \pm 0.99$ \\
\hline 16 & P,P-DDE & 13.3 & 2.0 & 0.01 & $85.67 \pm 1.12$ & $83.69 \pm 0.77$ & $92.68 \pm 0.96$ \\
\hline 17 & Dieldrin & 14.2 & 2.0 & 0.01 & $87.65 \pm 1.26$ & $84.53 \pm 1.41$ & $90.99 \pm 1.02$ \\
\hline 18 & O,P-DDD & 14.51 & 2.0 & 0.01 & $89.27 \pm 2.09$ & $88.77 \pm 0.9$ & $78.75 \pm 1.02$ \\
\hline 19 & Endrin & 15.02 & 2.0 & 0.01 & $86.71 \pm 1.51$ & $85.39 \pm 0.78$ & $95.26 \pm 0.25$ \\
\hline 20 & Beta-endosulfan & 15.41 & 2.0 & 0.05 & $87.62 \pm 1.97$ & $90.10 \pm 0.14$ & $99.0 \pm 0.29$ \\
\hline 21 & O,P-DDT & 16.01 & 2.0 & 0.01 & $88.92 \pm 1.10$ & $85.21 \pm 0.90$ & $90.29 \pm 0.61$ \\
\hline 22 & Propconazol & $17.55,17.9$ & 12 & 0.01 & $99.89 \pm 2.0$ & $95.32 \pm 1.22$ & $101.07 \pm 0.22$ \\
\hline 23 & P,P-DDT & 17.68 & 0.4 & 0.01 & $96.41 \pm 1.12$ & $98.26 \pm 0.22$ & $107.08 \pm 2.11$ \\
\hline 24 & Epoxiconazol & 19.61 & 4.0 & 0.01 & $96.75 \pm 1.20$ & $96.57 \pm 1.26$ & $94.50 \pm 2.71$ \\
\hline 25 & Acetamiprid & 20.5 & 2.0 & 0.06 & $88.87 \pm 0.94$ & 0.00 & 0.00 \\
\hline 26 & Brompropelate & 20.8 & 4.0 & 0.05 & $90.66 \pm 1.74$ & $92.22 \pm 0.28$ & $99.29 \pm 1.45$ \\
\hline 27 & Tetramethrin & 21.19 & 40 & 0.09 & $102.80 \pm 0.50$ & $90.12 \pm 1.86$ & $88.07 \pm 1.15$ \\
\hline 28 & Tetradifon & 21.29 & 2.0 & 0.05 & $95.26 \pm 0.55$ & $90.90 \pm 1.53$ & $93.42 \pm 0.97$ \\
\hline 29 & $\begin{array}{l}\text { Lampada- } \\
\text { cyhalothrin }\end{array}$ & $22.42,24.96$ & 6.4 & 0.01 & $88.09 \pm 1.21$ & $88.89 \pm 0.25$ & $95.40 \pm 1.18$ \\
\hline 30 & Permithrin & $27.27,27.75$ & 40 & 0.01 & $99.60 \pm 0.94$ & $99.27 \pm 0.35$ & $103.70 \pm 1.92$ \\
\hline 31 & Prochloraz & 28.06 & 8.0 & 0.01 & $74.81 \pm 0.21$ & $90.86 \pm 2.01$ & $71.65 \pm 0.84$ \\
\hline 32 & Cyfluthrin & $\begin{array}{c}29.74,30.18 \\
30.5,30.72\end{array}$ & 20 & 0.01 & $92.98 \pm 0.38$ & $86.90 \pm 0.15$ & $90.66 \pm 1.39$ \\
\hline 33 & Cypermethrin & $\begin{array}{l}31.06,31.59 \\
31.91,32.14\end{array}$ & 20 & 0.05 & $89.75 \pm 0.84$ & $90.04 \pm 0.12$ & $95.99 \pm 1.03$ \\
\hline 34 & Fenvalerate & $35.86,37.29$ & 20 & 0.01 & $91.37 \pm 0.79$ & $91.34 \pm 1.24$ & $97.49 \pm 1.17$ \\
\hline 35 & Deltamethrin & 41.39 & 10 & 0.05 & $90.0 \pm 0.73$ & $88.31 \pm 0.12$ & $93.41 \pm 1.36$ \\
\hline
\end{tabular}

Method_1 (ethyl acetate), Method_2 (n-hexane) and Method_3 (petroleum ether : ethyl acetate 80:20 v/v) 


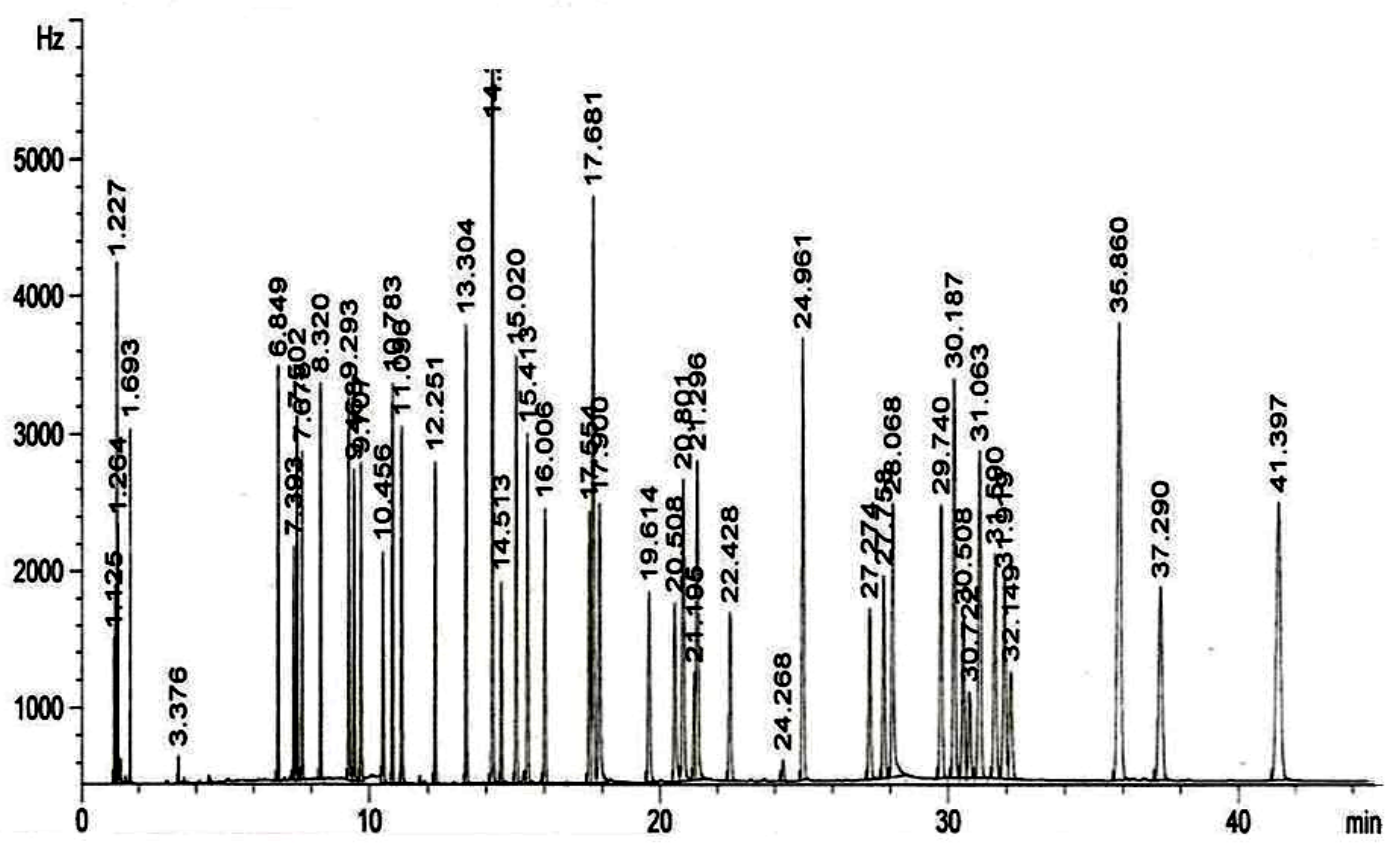

Fig.1. GC-ECD chromatogram of mixed pesticides standard solution

Table 2. Mean recoveries for three methods and standard error

\begin{tabular}{|c|c|c|}
\hline Method & Mean \pm S.E. & group \\
\hline Method_1 & $82.78 \pm 0.112 \mathrm{bc}$ & $\mathrm{a}$ \\
Method_2 & $77.69 \pm 0.112 \mathrm{ac}$ & $\mathrm{b}$ \\
Method_3 & $81.25 \pm 0.112 \mathrm{ab}$ & $\mathrm{c}$ \\
\hline
\end{tabular}

ECD parameters observed a good separation of thirty five pesticides belongs to different chemical groups within less than 45 minutes. It is agreed that ECD is more sensitive. Sensitivity of the method is also based on other factors such as detector sensitivity to the compound which expressed as the concentration factor, extraction method, volume injected into GC and mode of injection.

Regarding the potential of pesticides on human health and in environmental sources (water, soil and plant ..etc.), have led to establish a wide range of monitoring and risk assessment programs by governments and federal research centers. So, the monitoring of pesticides pollution in honey is very important and it can be use as an indicator to environmental pollution.

\section{REFERENCES}

Blasco C.; C.M. Lino; Y. Pico, G. Font and M.I.N. Silveira (2004). Determination of organochlorine pesticide residues in honey from the central zone of Portugal and the Valencian community of Spain, J. Chroma. A, 1049: 155-160.

Council Directive 2001/110/EC of 20 December 2001 Relating to Honey, Official Journal of the European Communities.

Fernandez M.A.; M.T. Sancho; S. Munitegui; J.F. Huidobro and J. Simal-Lozano, (1995). Nonacaricide Pesticide Residues in Honey: Analytical Methods and Levels Found, J. Food Protect. 58(11): 1271-1274.

Fernandez M.; Y. Pico and J. Manes (2002). Analytical Methods for Pesticide Residue Determination in Bee Products. J. Food Protect. 65(9): 1502-1511.

Herrera, A.; C. Perez-Arquillue; P. Conchillo; S. Bayarri; R. Lazaro; C. Yague and A. Arino, (2005). Determination of pesticides and PCBs in honey by solid-phase extraction cleanup followed by gas chromatography with electron-capture and nitrogen-phosphorus detection. Anal. Bioanal. Chem. 381(3): 695-701.

Jimenez, J.J.; J.L. Bernal; M.J. Del Lozal; L. Toribio and M.T. Martyn, (1998). Gas chromatography with electron-capture and nitrogen- 
phosphorus detection in the analysis of pesticides in honey after elution from a florisil column. J. Chromatgr. A, 823: 381-387.

Marzycka B. (2002). Simple method for the determination of trace levels of pesticides in honeybees using matrix solid-phase dispersion and gas chromatography. J. Chromatgr. A, 982: 267-272.

Pico, Y.; E. Viana; G. Font and J. Manes, (1995). Determination of organochlorine pesticide content in human milk and infant formulas using solid phase extraction and capillary gas chromatography. J. Agric. Food Chem. 43: 1610-1615.

Tahboub, Y.R.; M.F. Zaater and T.A. Barri (2006). Simultaneous identified and quantitation of selected organochlorine pesticide residues in honey by full-scan gas chromatography-mass spectrometry, Analytica Chimica Acta 558: 6268.

Tsipi D.; M. Triantafyllou and A. Hiskia (1999). Determination of organochlorine pesticide residues in honey, applying solid phase extraction with RPC18 material. Analyst, 124: 473-475.

Zhen, J.; L. Zhuguag; C. Meiyu; M. Yu; T. Jun; F. Yulan; W. Jiachen; C. Zhaobin and T. Fengzhang (2006). determination of multiple pesticide residues in honey using gas chromatographyelectron impact ionization-mass spectrometry. Chinese Journal of Chromatography, 24(5): 440-446. 